\title{
INVALIDITY OF ISOTHERMAL ANALYSIS IN ESTIMATING THE THERMAL PERFORMANCE OF STIRLING ENGINE AND CRYOCOOLER
}

\author{
Hailaa Jabbar Kareem ${ }^{1}$ \\ hailaak527@uowasit.edu.iq
}

\author{
Ali A. F. Al-Hamadani² \\ aalhamadani@uowasit.edu.iq
}

\author{
Ali Noaman Ibrahim ${ }^{3}$ \\ eng.ali.noman@uobabylon.edu.iq
}

1,2 University of Wasit- College of engineering-Department of Mechanical Engineering.

${ }^{3}$ University of Babylon- College of engineering-Department of Mechanical Engineering.

\section{ABSTRACT}

The Stirling engine is an external heat engine, which is considered as the best option for extracting work from concentrated solar power applications. The most prominent characteristics of the engine are low noise, vibration, and emissions besides reflexivity of usage with any kind of heat source such as solar, biomass, industrial heat, etc. In the present paper, the STE-1008 gamma-type Stirling engine had been analyzed by using an isothermal model to demonstrate the failure of the model in analyzing the STE-1008 considering it firstly as an engine and secondly as a cryocooler. The energy equation had been used to demonstrate the disability of the isothermal model in achieving a successful thermal analysis for engine performance. In addition, a MATLAB code had been developed to check the credibility of the isothermal model in the estimation of the engine thermal parameters. The findings of the isothermal analysis revealed that the heat exchangers are unnecessary. But, in reality; all the necessary heat transfer occur within the heat exchangers rather than in the working space boundaries. Therefore, that is invalid conclusion. However, Schmidt's theory is capable of capturing the essential engine features superbly. In particular, it is capable of capturing the fundamental interplay between the mechanically restricted movement of the engine components as well as the thermodynamic cycle which is obtained from this theory.

$$
\text { عدم صلاحيّة التحليل المتساوي درجة الحرارة في تقدير الأداء الحراري لمحرِّك ومبرّد }
$$

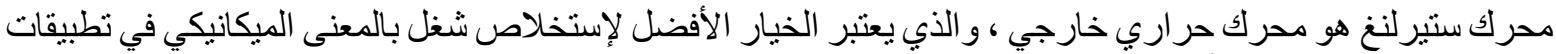

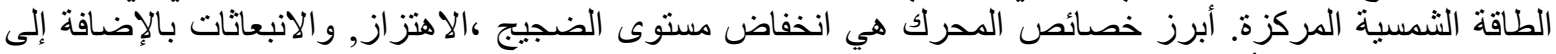

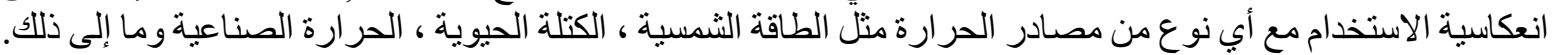

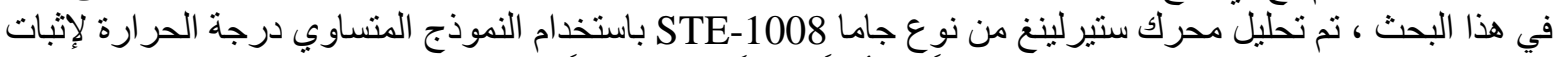

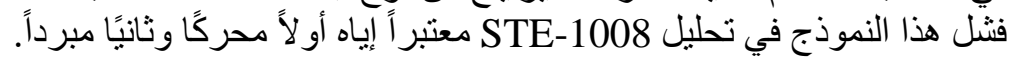




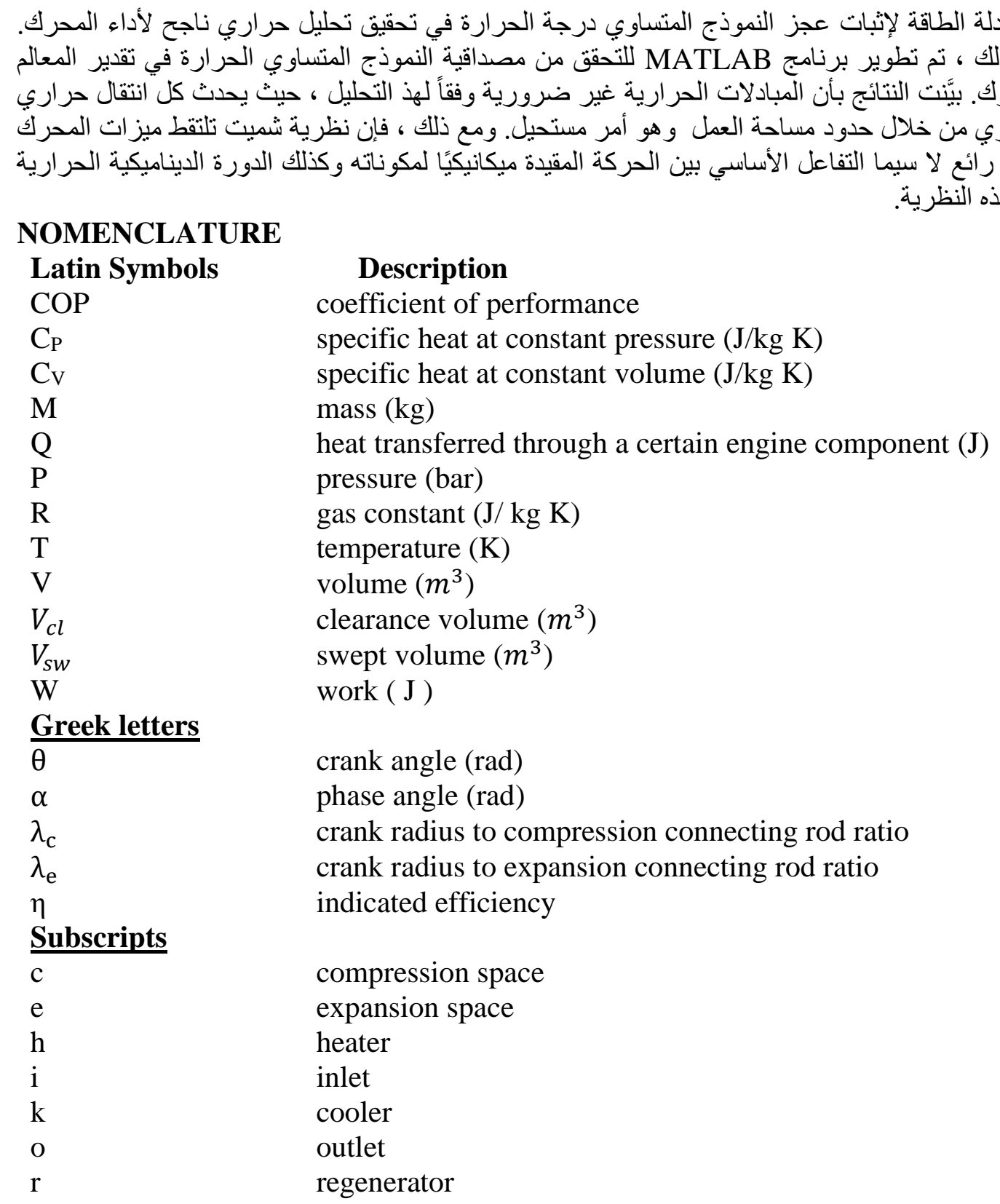

e expansion space

h heater

crank angle (rad)

phase angle (rad)

crank radius to compression connecting rod ratio crank radius to expansion connecting rod ratio indicated efficiency

compression space

\section{INTRODUCTION}

Recently, the problem of wasted heat from an industrial establishment is one among many problems which are directly affecting the environment. In an internal combustion engine, the chemical energy of the fuel is converted into heat by combustion in a complete thermodynamic cycle. Then, the remainder of the energy is released into the atmosphere as waste heat from cooling water and exhaust gases (He et al., 2011). One way to compensate the wasted heat is using an external heat engine (such as the Stirling engine). Practically, the Stirling engine works with a large variety of inexpensive working fluids such as: air, helium, and nitrogen. In addition, Stirling engine can be operated by multiple heat sources such as biomass, solar, or even industrial excess heat (Flynn, Percival and Heffner, 1960). The engine was invented by Church of Scotland minister Robert Stirling in 1816 but the concept of regenerative was not understood until 1871 (Vineeth C S, 2011). Its thermodynamic cycle consists of four processes isothermal compression, isochoric heat addition, isothermal expansion, and isochoric heat rejection respectively. Stirling engines were originally divided into groups based on their geometric layout. 
Practically, three configurations of the Stirling engine are available: Alpha, Beta, and Gamma (Tlili, 2012). The engine also could be used as a cryocooler by reversing the three configurations' thermodynamic cycle, where Herschel suggested reversing the cycle and using it as a refrigerator for ice production In 1834 (Klaus D. Timmerhaus, 2007). Later Kohler and Jonkers created a tiny air liquefier based on the principle of the Stirling engine in 1954 and at lower temperatures, they developed larger air liquefiers and two-stage systems (Guglielmo Ventura, 2008). Schmidt rendered classical analysis of engine cycle in 1871 and obtained close theory, which provides sinusoidal volume variation of working space in the reciprocating engines (Thombare and Verma, 2008). This analysis is known as an ideal isothermal analysis or Schmidt theory that has many assumptions to get the best performance for both engine and cryocooler. Many researchers have used several methods and software to analyze various types of Stirling engines. (Walker, 1962) optimized the dimensionless Schmidt equations to four parameters: temperature ratio, dead volume ratio, swept volume ratio, and phase angle to give maximum Stirling engine output and maximum heat raised for the Stirling refrigerator using a Ferranti 'Pegasus' electronic digital computer. Detailed performance comparisons for both engine and refrigerator have revealed that the best results are most likely to be attained when the machine is constructed with a limited maximum cycle pressure. (F. A. Creswick, 1965) made a thermal design of Stirling cycle machines which included the selection of the regenerator design as well as the selection of surfaces that transmit heat between the working fluid and the heat of source-sink arrangement by using two ways: ideal isothermal Schmidt and conventional heat exchanger design techniques. (Walker, 1974) performed a Schmidt analysis using a compound working fluid on the Stirling cooling engine. The compound working fluid consisted of two components: one acting at all times as a perfect gas and the other being present in the liquid state at cooling temperatures $\left(\mathrm{T}_{\mathrm{e}}\right)$ in the expansion space and in the vapor state at near-ambient temperature $\left(\mathrm{T}_{\mathbf{c}}\right)$ in the compression space. A preliminary study had shown that the use of a compound working fluid can allow a significant improvement in the cooling ability within comparable limits of size, weight, and cost. (Organ, 1979) recast the ideal isothermal analysis of the practical Stirling cycle so that any equation of state could be solved numerically. The analysis was carried out on a Stirlingrefrigerator by using a working gas behaved as van der Waals' gas. The results proved that the amount of work is less and heat transported is greater than expected in the expansion space so it is necessary to take care in the selection of operating pressures when certain gases are used as working fluids in reversed Stirling-cycle machines. (Senft, 1987) presented a general theory of the mechanical efficiency of kinematic heat engines. First, the research implemented the conceptual basis for the energy transfers between the core components of the reciprocating thermal engines. Second, it showed that the ideal Stirling engine has the highest mechanical efficiency potential and this provides the absolute upper limit to the mechanical efficiency of all kinematic engines. (Zhu and Chen, 1994) introduced an isothermal model analysis for pulse tube Stirling refrigerators. The main assumption of the model is considering the gas subjecting to an adiabatic process in the middle portion of the pulse tube, whereas it is subjected to an isothermal process in the other parts. The findings of the research (Zhu and Chen, 1994) are compared with the results of the nodal analysis (Shaowei, Peiyi and Zhongqi, 1990) conducted on the same refrigerator. The gross cooling power and the input power used by the isothermal model are $20 \%$ lower than the values obtained by the nodal model. The pressure ratio and the average mass flow rate are about 5 percent lower using the isothermal model. (Nellis and Maddocks, 2003) presented a first-order analysis (isothermal analysis) of a hybrid system that combines a two-piston Stirling cycle with a perfect regenerator and isothermal compression and expansion spaces with a reverse-Brayton stage. The isothermal Schmidt analysis of the Stirling cycle had been extended by developing additional 
dimensionless governing equations, which characterize the recuperative system. Variables in the swept volume ratio and phase angle were employed to optimize the hybrid system design to maximize the refrigeration per unit of heat transfer in the recuperator and regenerator. Both of the recuperator and the regenerator are heat exchangers but the difference between them that the recuperator transfers heat directly while in the regenerator the transfer of heat is not directly (McDonald and Wilson, 1996). The findings of (Nellis and Maddocks, 2003) revealed that there is an optimal phase angle and swept volume ratio for maximizing the amount of heat recovered from the recuperative stage per load on the heat exchangers (regenerator and recuperator). The optimal phase angle is slightly higher than in a "pure" Stirling system, while the optimal swept volume ratio is significantly higher. (Gussoli, Oliveira and Higa, 2020) used the isothermal model to compare between two ways of volume variation in alpha type Stirling engine: sinusoidal and kinematic. The results revealed that for an isothermal model, the little difference in volume variation methods did not have as much of an impact on the output as the working fluid mass calculation. Nonetheless, both the sinusoidal and kinematic techniques for analyzing alpha Stirling engines are valid methodology. All the aforementioned papers have used the Schmidt theory as a basis in analyzing and predicting the performance of the Stirling engine although the Schmidt theory is an ideal isothermal analysis that cannot happen in real machines (especially Stirling engine) which tend to be adiabatic rather than isothermal. To have a valuable insight of using Schmidt analysis in real design or improvement of Stirling engine, the present paper investigates the points of strength and weakness of using the isothermal model in analyzing the thermal performance of Stirling machine whether it is used as an engine or a cryocooler. It is an attempt to provide enough information about the advantages and disadvantages of using Schmidt theory in a realistic engine design (or performance evaluation) in order to analyze the Stirling engine cautiously avoiding any serious mistake may result from improper use of that theory. All the conclusions will be demonstrated depending on the STE-1008 gamma-type Stirling machine as a basis of analysis. The results show that the indicated efficiency is $69 \%$ and the coefficient of performance is 6.163 as Schmidt theory has been used in the analysis.

\section{Thermodynamic Cycle of Stirling Machine}

For Stirling machine, the thermodynamic cycle consists of two isothermal and two isochoric processes. The cycle of the machine (including the engine and cryocooler) is described follows:

\section{Engine cycle}

The assumption adopted is the compression space piston is at the outer dead point and that the expansion space piston is close to the regenerator at the inner dead point (Thombare and Verma, 2008). The thermodynamic processes shown in Figure (1) are:

- Isothermal compression (1-2)

- Isochoric heat addition (2-3)

- Isothermal expansion (3-4)

- Isochoric heat rejection (4-1)

\section{Stirling cryocooler cycle}

By reversing the engine cycle, it will operate as a cryocooler at different temperatures and pressures. The sequence of operations for the cycle of a Stirling cryocooler pressed with the working gas as follows (Ackermann, 1997):

- Isothermal compression (4-3)

- Isochoric heat rejection (3-2)

- Isothermal expansion (2-1) 
- Isochoric heat addition (1-4)

\section{Stirling Machine Evaluation}

This analysis is based on the classical Schmidt theory. It provides a harmonic motion for the reciprocating components but maintains the key principles of perfect regeneration, isothermal compression, and isothermal extension (Walker, 1980). The assumption of the perfect regenerator leads to consider the internal void volume as zero and the successive expansion and compression processes to be always isothermal. Nevertheless, this theory can provide a good estimate for a number of the crucial engine parameters (Abdullah, Yousif and Sopian, 2005).

\section{Schmidt Theory}

STE-1008 design is selected in the present work as a sample on which Schmidt theory have been applied and inspected. We have access to all of STE-1008 design parameters along with the geometry map, which we have bought from a third-party company (Stirling School of Engines) connected with Irankhodro Powertrain Company (Sterling engine - Iran Khodro engine research, design and production company information portal). As a result, Schmidt theory have been applied to evaluate the STE-1008 engine performance with the developed MATLAB code analyzing the most important parameters, including but not restricted to the work of compression and expansion cylinders, the total mass of gas in the engine, the indicated efficiency of the engine, and the coefficient of performance of the cryocooler. For this theory, the following assumptions have been made (Walker, 1980):

1. The regenerative process is perfect.

2. The instantaneous pressure is constant throughout the engine.

3. The working gas obeys the ideal gas law.

4. The total mass of the working gas remains constant.

5. The volume variation in the working space has occurred sinusoidally.

6. The temperature of the working gas in all ancillary spaces is assumed to be constant. The volumes variations for compression and expansion are (Alfarawi, AL-Dadah and Mahmoud, 2016):

$$
\begin{aligned}
V_{C}= & V_{c l c}+\frac{V_{s w e}}{2}\left[1+\cos \theta-\frac{1}{\lambda_{e}}\left(1-\sqrt{1-\lambda_{e}{ }^{2} \sin \theta^{2}}\right)\right]+\frac{V_{s w c}}{2}[1-\cos (\theta-\alpha)+ \\
& \left.\frac{1}{\lambda_{c}}\left(1-\sqrt{1-\lambda_{c}{ }^{2} \sin (\theta-\alpha)^{2}}\right)\right] \\
V_{e}= & V_{c l e}+\frac{V_{s w e}}{2}\left[1-\cos \theta+\frac{1}{\lambda_{e}}\left(1-\sqrt{1-\lambda_{e}{ }^{2} \sin \theta^{2}}\right)\right]
\end{aligned}
$$

The instantaneous pressure is a function to the compression and expansion volumes in the engine (Thombare and Verma, 2008 ):

$$
P=\frac{m_{\text {total }} R}{\frac{V_{c}}{T_{c}}+\frac{V_{k}}{T_{k}}+\frac{V_{r}}{T_{r}}+\frac{V_{h}}{T_{h}}+\frac{V_{e}}{T_{e}}}
$$

where $T_{r}$ is the effective regenerator temperature which can be calculated by assuming that the temperatures of the compression and expansion spaces are distributed linearly in the regenerator as following (Thombare and Verma, 2008):

$T_{r}=\frac{T_{h}-T_{k}}{\ln \left(\frac{T_{h}}{T_{k}}\right)}$

The total mass of the working fluid in the engine is (Thombare and Verma, 2008 ):

$\mathrm{m}_{\text {total }}=m_{c}+m_{k}+m_{r}+m_{h}+m_{e}$ 
According to the assumption of the theory, both the compression space and the cooler are working at sink temperature $\left(T_{c}=T_{k}\right)$, while the heater and the expansion space are working at hot source temperature $\left(T_{h}=T_{e}\right)$ as shown in Figure (2). For the cryocooler, the compression space and the cooler are working at ambient temperature $\left(T_{c}=T_{k}\right)$ and the freezer and the expansion space are working at surrounding temperature $\left(T_{f}=T_{e}\right)$.

Accordingly, the pressure for engine and cryocooler respectively become (Thombare and Verma, 2008):

$P=\frac{m_{\text {total }} R}{\frac{V_{c}}{T_{k}}+\frac{V_{k}}{T_{k}}+\frac{V_{r}}{T_{r}}+\frac{V_{h}}{T_{h}}+\frac{V_{e}}{T_{h}}}$

$P=\frac{m_{\text {total }} R}{\frac{V_{c}}{T_{k}}+\frac{V_{k}}{T_{k}}+\frac{V_{r}}{T_{r}}+\frac{V_{f}}{T_{f}}+\frac{V_{e}}{T_{f}}}$

Simplifying the equation of pressure by substituting equations $1 \& 2$ in equation 6 (or 7 for cryocooler):

$P=\frac{m_{\text {total }} R}{S(1+b \cos \emptyset)}$

$\mathrm{S}, \mathrm{b}$ are constants and $\emptyset=\theta+\beta$. By integrating the above equation get the average pressure over the cycle ( Thombare and Verma, 2008 ):

$P_{\text {mean }}=\frac{1}{2 \pi} \int_{0}^{2 \pi} P d T$

$P_{\text {mean }}=\frac{m_{\text {total }} R}{S \sqrt{1-b^{2}}}$

The algebraic sum of the work done by compression and expansion spaces equals the net work done by the engine ( Thombare and Verma, 2008 ):

$W=W_{c}+W_{e}$

$W=\oint P d V_{c}+\oint P d V_{e}$

$W=\int_{0}^{2 \pi} P\left(\frac{d V_{c}}{d \theta}+\frac{d V_{e}}{d \theta}\right) d \theta$

For engine the power output and the indicated efficiency of the isothermal analysis is (Thombare and Verma, 2008):

Power $=W \times \frac{\omega}{60}$

$\eta_{\text {iso }}=\frac{\mathrm{w}}{\mathrm{w}_{\mathrm{e}}}$

On the other hand, for cryocooler the coefficient of performance of the isothermal analysis is (Van Sciver, 2012):

$\mathrm{COP}_{\text {iso }}=\frac{\mathrm{w}_{\mathrm{e}}}{\mathrm{W}}$

Each Stirling engine component is thought of as a single cell that compresses and expands a working fluid mass flow as shown in Figure (3) (Ferreira et al., 2016). The energy equation is used to determine the heat transfer to the heater and from the cooler as follows (Thombare and Verma, 2008):

Rate of heat transfer into the cell + Net enthalpy converted to cell

$=$ Rate of work done on surrounding

+ Rate of increase of internal energy in the cell

$D Q+\left(C_{p} T_{i} m_{i}-C_{p} T_{o} m_{o}\right)=D W+C_{v} D(m T)$ 
In the isothermal analysis, we have $\left(T_{i}=T_{o}=\mathrm{T}\right) \&\left(m_{o}-m_{i}=D m\right)$ for the compression and expansion spaces as well as the heater and cooler. Therefore, the energy equation becomes (Thombare and Verma, 2008):

$D Q=R T D m+D W$

Where $R=C_{p}-C_{v}$

Using cyclic integration of the equation (15), the net heat transferred to the working gas over the period is calculated as follow (Thombare and Verma, 2008):

$Q=R T \oint D m+\oint D W$

This means that both of temperature and mass of the working fluid is constant over the cycle, and there is no work done in the heat exchangers thus the heat transfer rates can be expressed as:

$\left.\begin{array}{c}Q_{c}=W_{c} \\ Q_{k}=0 \\ Q_{r}=0 \\ Q_{h}=0 \\ Q_{e}=W_{e}\end{array}\right\}$

The work of expansion and compression spaces $\left(W_{e}\right.$ and $\left.W_{c}\right)$ is calculated from eq. (11) by integrating each of them separately.

\section{MATLAB Code}

All the above equations of the isothermal analysis have been written and solved in MATLAB code as shown in the figure (4).

\section{Stirling Machine Description}

The STE-1008 gamma-type Stirling engine design mapping have been purchased from Iran Khodro Industrial Group (Sterling engine - Iran Khodro engine research, design and production company information portal). The engine that is shown in Figure (5) consists of compression and expansion spaces and three heat exchangers: cooler, regenerator, and heater. The cooler is an internal finned circular duct provided with 144 fins where the section area of each fin is $10.5 \mathrm{~mm}$ by $1 \mathrm{~mm}$ and around it there is a water circulated in a water jacket to rejects heat at cold sink temperature. The heater is comprised of 20 tubes with $8 \mathrm{~mm}$ inner diameter, which absorbs heat from surrounding at hot source temperature. The annular regenerator is located in the heater head below the expansion space where the displacer passes through it. It can be considered as a thermodynamic sponge equipped with a random fiber matrix of $31 \mu \mathrm{m}$ wire diameter and $90 \%$ porosity that receives heat from the hot flow alternately and then releases it to the cold flow all details are given in Table 1. While the Stirling cryocooler consists of compression and expansion spaces and three heat exchangers: cooler, regenerator, and freezer. The cooler and freezer are similar to cooler and heater of the engine but the cooler rejects heat to cyclic water at ambient temperature while the freezer absorbs heat from the surrounding at cold temperature.

\section{RESULTS AND DISCUSSION}

\section{Stirling Engine}

Figure (6) shows the variation of the total volume inside the engine with pressure. The $\mathrm{x}$-axis represents the total volume in engine where it is the sum of the volumes of five components $\left(V_{c}, V_{k}, V_{r}, V_{h}, V_{e}\right)$, while the y-axis represents the pressure that calculated from equation (3). By integrated the area under the P-V diagram the total work of the engine is obtained $W_{\text {total }}=496.6 \mathrm{~J}$, the compression space work is $W_{c}=-225.6 \mathrm{~J}$, and the expansion space 
work is $W_{e}=721.8 \mathrm{~J}$. In addition, the total mass of the working fluid that obtained from the equation of state of an ideal gas at $923 \mathrm{~K}$ source temperature, $288 \mathrm{~K}$ sink temperature, $10 \mathrm{bar}$ charge pressure, and $500 \mathrm{rpm}$ is $m_{\text {gas }}=0.00154 \mathrm{~kg}$. The indicated efficiency of the isothermal model is $\eta=69 \%$ and the power reached to Power $=4.137 \mathrm{~kW}$.

Figure (7) shows the relationship between mean pressure and the angle of the crankshaft. The charge pressure that represented by the red solid line is constant in all components of the engine. The maximum pressure in the thermodynamic cycle is, $P_{\max }=13.8$ bar at $\theta=120^{\circ}$, while the minimum pressure is, $P_{\min }=7.2$ bar at $\theta=330^{\circ}$.

\section{Stirling cryocooler}

For cryocooler, the results that obtained from the MATLAB code with operating conditions of $298 \mathrm{~K}$ ambient temperature, freezing temperature $256.4 \mathrm{~K}, 3 \mathrm{bar}, 500 \mathrm{rpm}$., the operation conditions are $298 \mathrm{~K}$ ambient temperature, $256.4 \mathrm{~K}$ freezer temperature, $3 \mathrm{bar}$, and $500 \mathrm{rpm}$. Figure (8) shows the variation of the total volume with the pressure. The integrated of the area under the p-v diagram gives the total work of the cryocooler. The mass is also obtained from the equation of state of an ideal gas as $m_{\text {gas }}=0.00105 \mathrm{~kg}$. The work of compression space is $W_{c}=-115.6 \mathrm{~J}$, the work of expansion space is $W_{e}=99.5 \mathrm{~J}$. Therefore, the total work is $W_{\text {total }}=-16.14 \mathrm{~J}$, and the coefficient of performance is $C O P=6 \cdot 163$.

Figure (9) shows the variation of the mean pressure with crank angle. The charge pressure of the cryocooler is $3 \mathrm{bar}$, maximum pressure is $P_{\max }=6.3 \mathrm{bar}$ at $\theta=25^{\circ}$ while the minimum pressure is $P_{\min }=2.9$ bar at $\theta=200^{\circ}$.

\section{The validation of the Model}

The MATLAB code that was used to perform the theoretical isothermal analysis of the STE-1008 gamma-type Stirling engine was validated where the experimental results of the STE-05 gamma-type Stirling engine that get from (Alfarawi, AL-Dadah and Mahmoud, 2016) are compared with the results of the MATLAB code for the same engine and at the same operation conditions. As shown in figure (10), the two p-v diagrams of STE-05 gamma-type Stirling engine showed a good match. As for the gaps between them, this is because the experimental results took into account the processes of heat transfer from and to the engine, which were neglected in the isothermal analysis.

\section{CONCLUSIONS}

The Stirling engine is an external heat engine that has many characteristics. It can use any kind of heat source such as solar, biomass, industrial heat. In the present work, the secondorder analysis method (the Schmidt theory) is used to quantify and interpret the performance of the STE-1008 gamma Stirling engine. On the basis of Schmidt theory, the study performed the analysis of five components: compression space, cooler, regenerator, heater, and expansion space. For the regenerator matrix, a random fiber of $31 \mu \mathrm{m}$ and 0.9 porosity is used. The indicated efficiency and coefficient of performance of helium is calculated at pressure 10 bar, hot temperature source $650^{\circ} \mathrm{C}$, and cold sink temperature at $15^{\circ} \mathrm{C}$ for the engine. 3 bars, $25^{\circ} \mathrm{C}$ ambient temperature, and $-16.6^{\circ} \mathrm{C}$ freezer temperature for cryocooler using MATLAB code. The indicated efficiency is $0.69 \%$ and the coefficient of performance is 6.163 . The results showed that the heat exchangers are redundant, all necessary external heat transfer occurring through the working space boundaries. This is not possible because the cylinder walls are not built to transfer heat. The working spaces in real machines will appear to be adiabatic rather than isothermal, implying that the heat exchangers must provide the net heat transferred over the cycle. However, Schmidt's theory captures the essential engine features superbly, particularly the fundamental interplay between the mechanically restricted 
movement of its components and the thermodynamic cycle that results.

Table1. Engine and cryocooler Specifications.

\begin{tabular}{|c|c|c|}
\hline Parameter & symbols & Description \\
\hline Rotational speed( rpm) & $\omega$ & 500 \\
\hline Stroke $(\mathrm{mm})$ & $\mathrm{L}$ & 75 \\
\hline Power piston diameter $(\mathrm{mm})$ & $d_{p}$ & 85 \\
\hline Displacer piston diameter (mm) & $d_{d}$ & 96 \\
\hline Working gas type & $\mathrm{He}$ & Helium \\
\hline Heater/Freezer type & $\mathrm{t}$ & Tubular \\
\hline Cooler type & $\mathrm{f}$ & Finned \\
\hline Regenerator type & $\mathrm{a}$ & Annular \\
\hline Wire diameter $(\mu \mathrm{m})$ & $d_{w}$ & 31 \\
\hline Porosity $(\%)$ & porosity & 0.9 \\
\hline \multicolumn{3}{|l|}{ For engine: } \\
\hline Charge pressure (bar) & $\mathrm{P}$ & 10 \\
\hline Cold sink temperature $\left({ }^{\circ} \mathrm{C}\right)$ & $T_{k}$ & 15 \\
\hline Hot source temperature $\left({ }^{\circ} \mathrm{C}\right)$ & $T_{h}$ & 650 \\
\hline \multicolumn{3}{|l|}{ For cryocooler: } \\
\hline Charge pressure (bar) & $\mathrm{P}$ & 3 \\
\hline Ambient temperature $\left({ }^{\circ} \mathrm{C}\right)$ & $T_{k}$ & 25 \\
\hline Freeze temperature $\left({ }^{\circ} \mathrm{C}\right)$ & $T_{f}$ & -16.6 \\
\hline
\end{tabular}

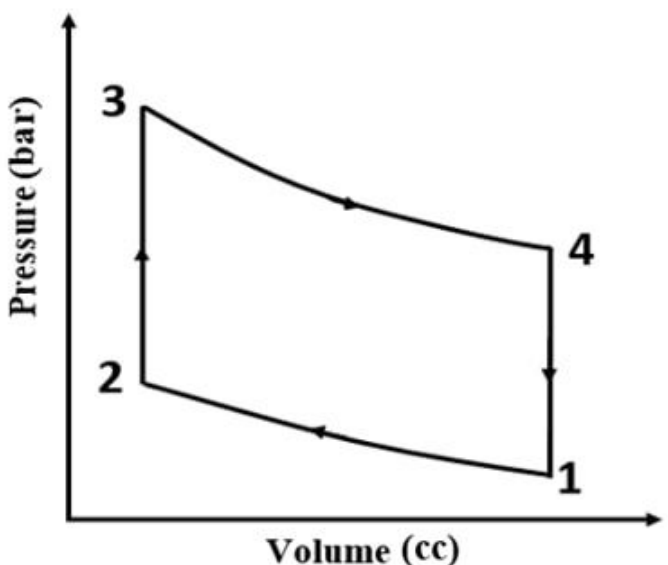

a) P-v diagram

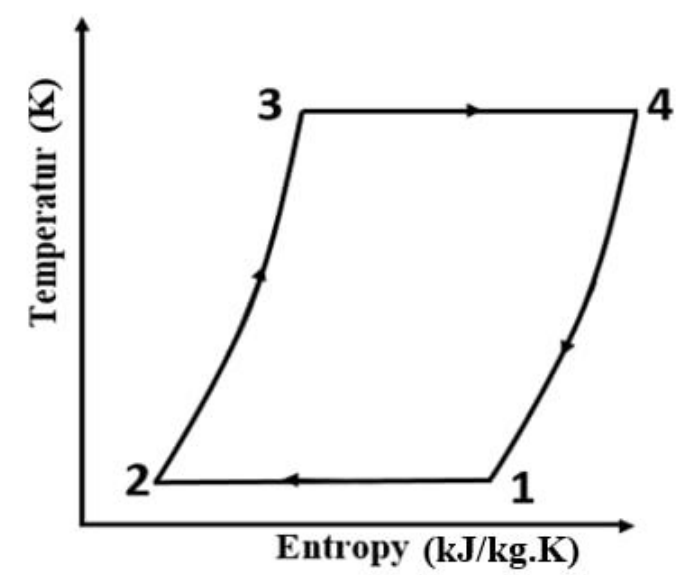

b) T-s diagram

Fig. 1. Thermodynamic cycle of Stirling machine. 


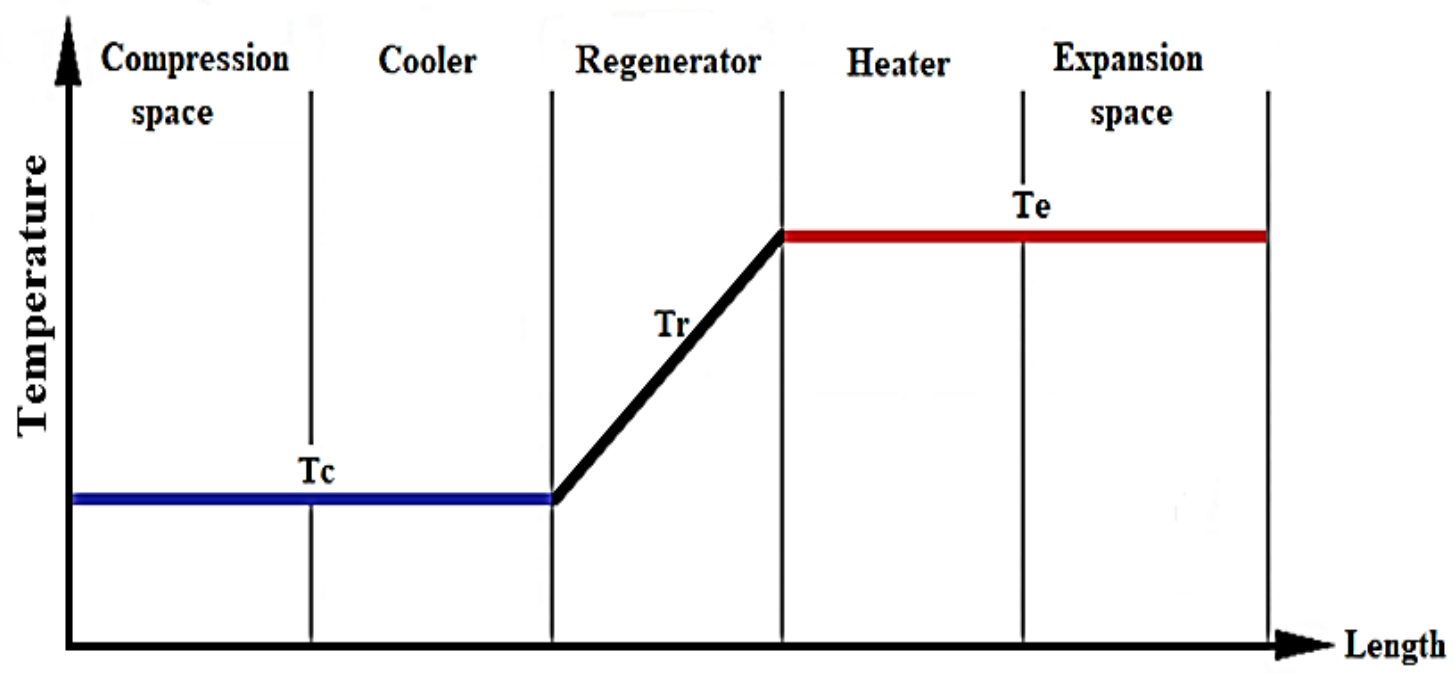

Fig.2. Temperatures distribution along the engine in the isothermal analysis.

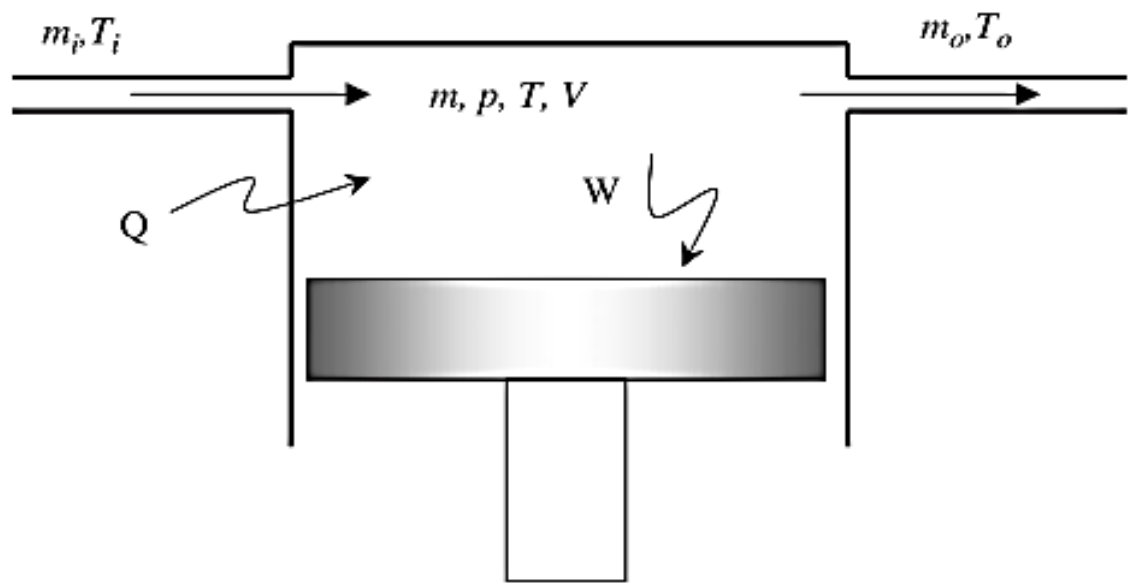

Fig. 3. A generalized cell of engine (Thombare and Verma, 2008). 


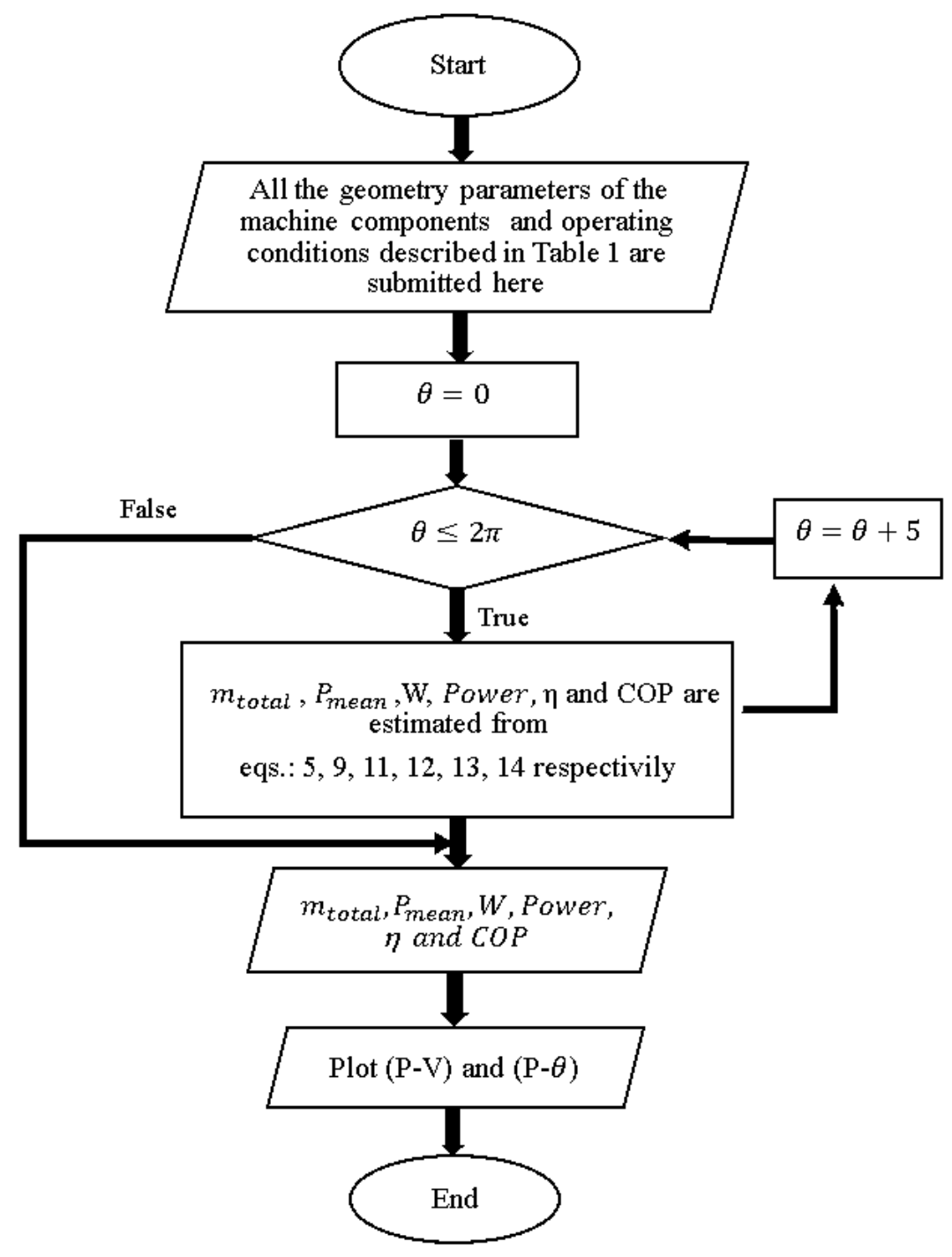

Fig. 4. Flow chart of the isothermal analysis code for Stirling machine.

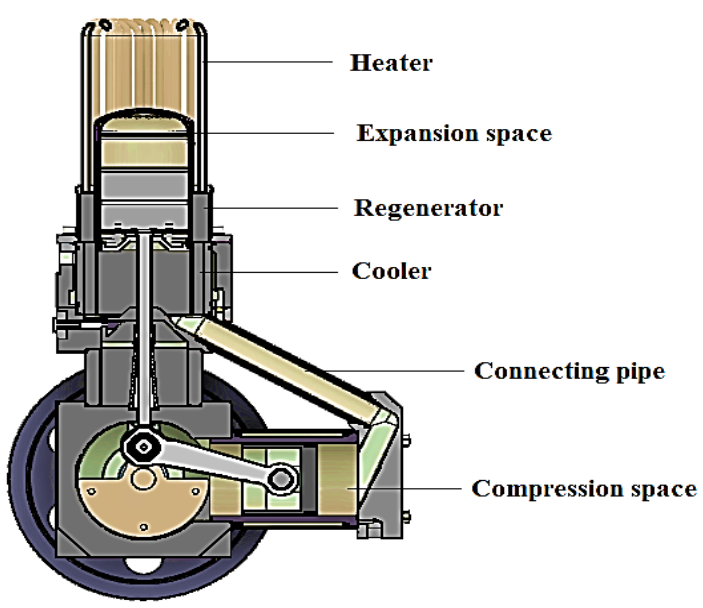

Fig. 5. STE-1008 gamma-type Stirling engine. 


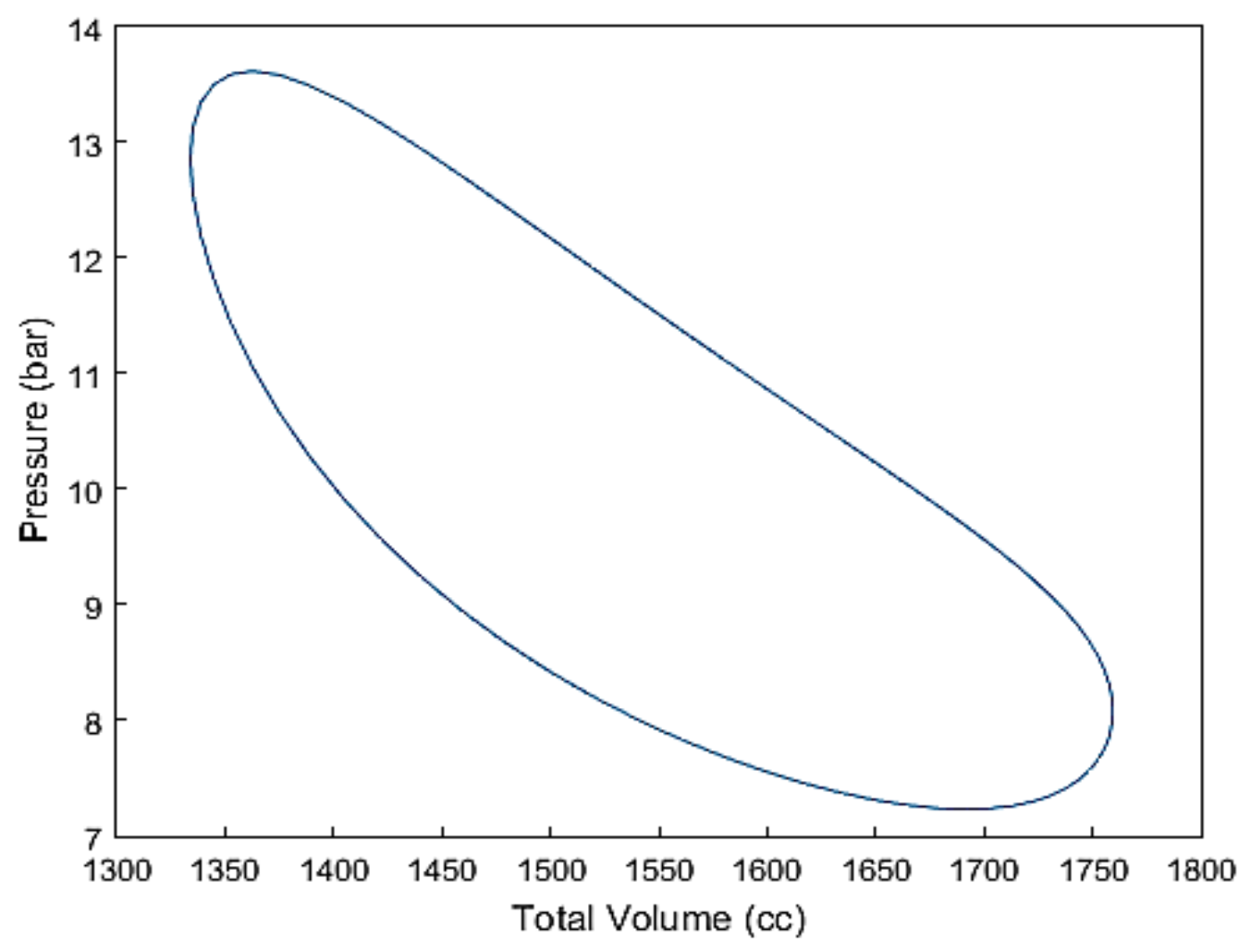

Fig.6. P-V diagram of STE-1008 engine.

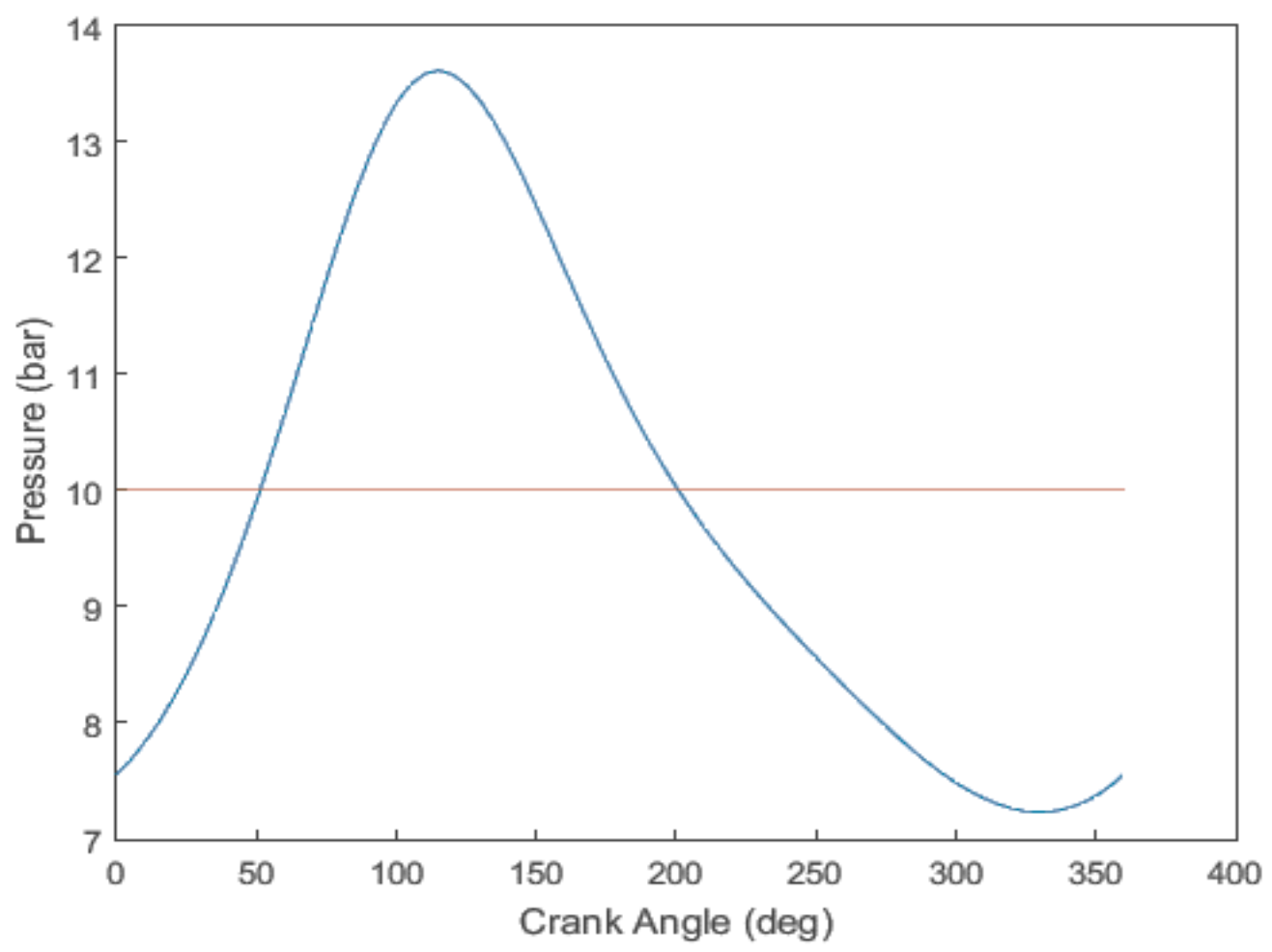


Fig.7. Pressure-crank angle of STE-1008 engine.

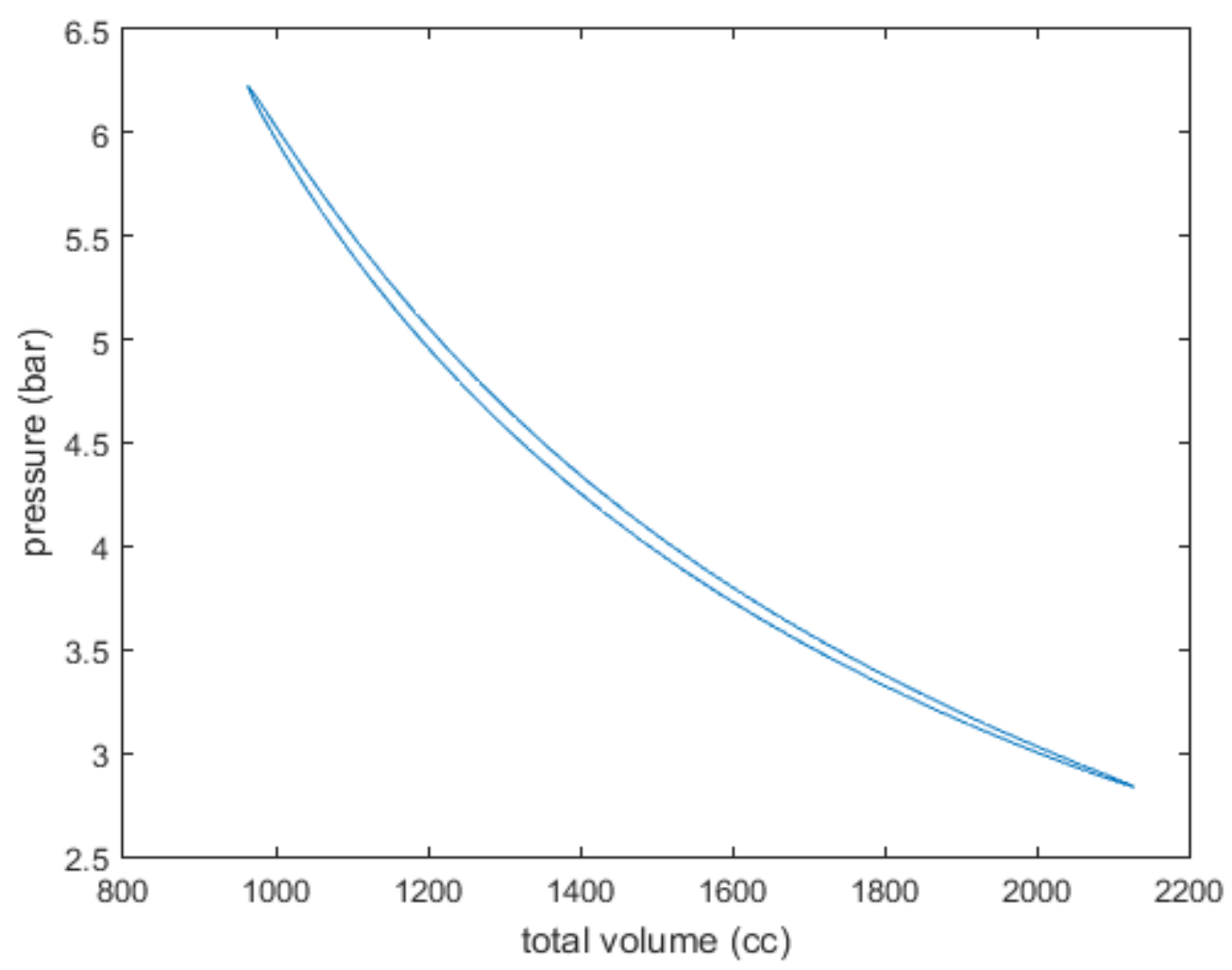

Fig.8. P-v diagram of STE-1008 cryocooler.

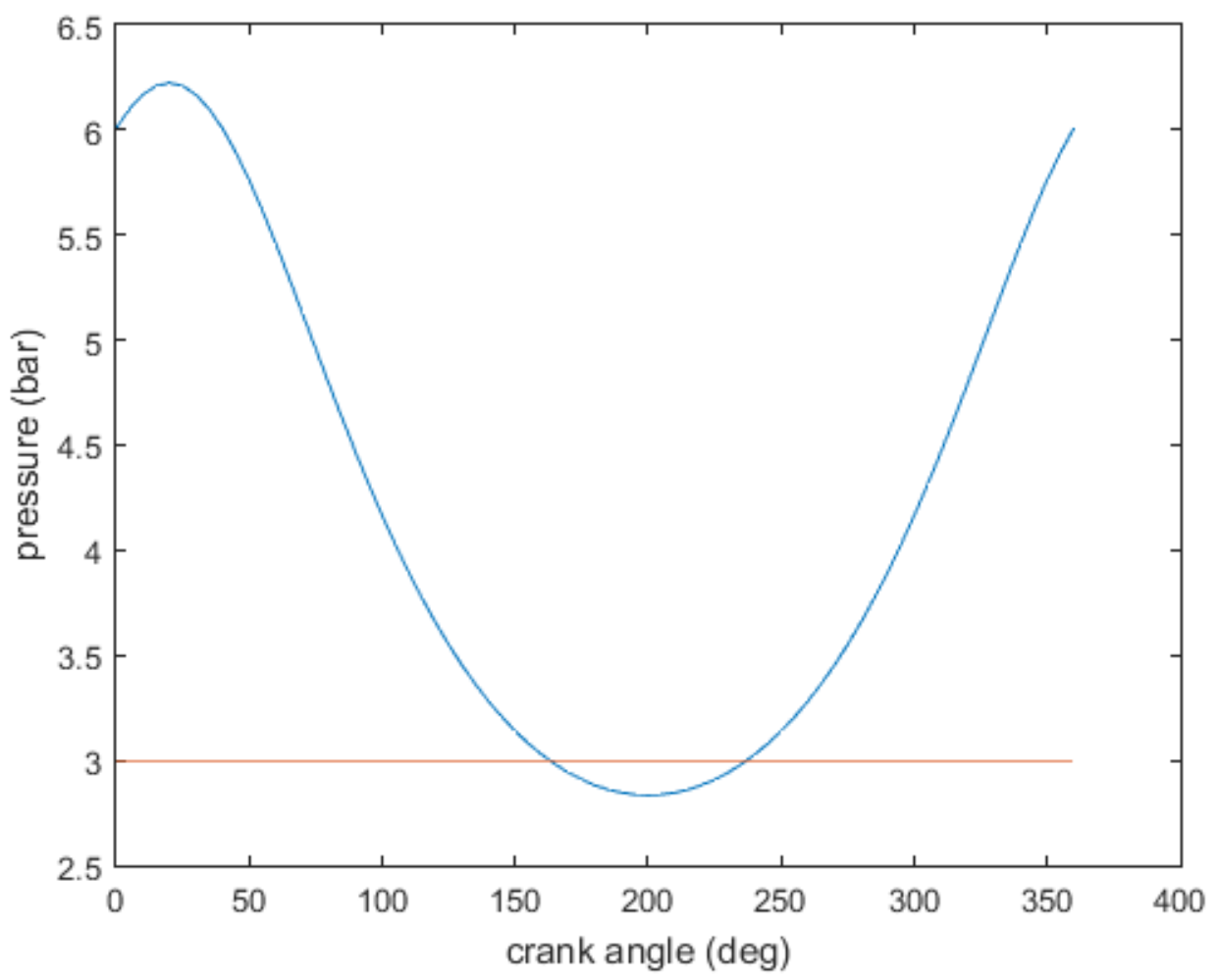


Fig.9. Pressure-crank angle of STE-1008 cryocooler.

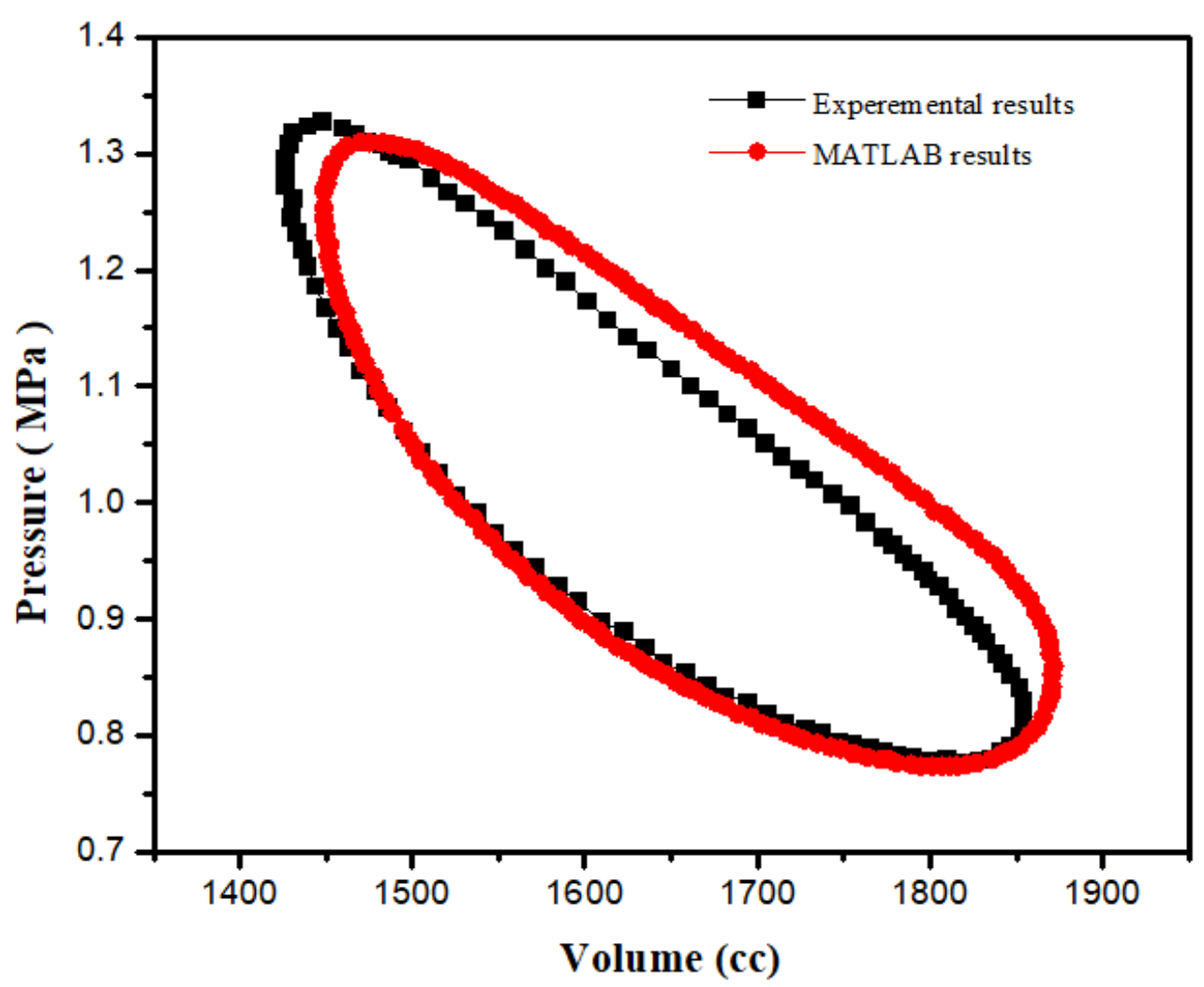

Fig.10. Validation between experimental and MATLAB results of STE-05 engine.

\section{REFERENCE}

Abdullah, S., Yousif, B. F. and Sopian, K. 'Design consideration of low temperature differential double-acting Stirling engine for solar application', Renewable Energy, Vol.30,No.12, pp. 1923-1941, 2005.

Ackermann, R. A., Cryogenic Regenerative Heat Exchangers, Boston, MA: Springer US. 1997.

Alfarawi, S., AL-Dadah, R. and Mahmoud, S., 'Influence of phase angle and dead volume on gamma-type Stirling engine power using CFD simulation', Energy Conversion and Management,Vol.124, pp. 130-140. 2016.

F. A. Creswick 'Thermal Design of Stirling-Cycle Machines', pp. 374-383. 1965.

Ana C. Ferreira, Manuel L. Nunes , Jose C.F. Teixeira, Luís A.S.B. Martins, Senhorinha F.C.F. Teixeira 'Thermodynamic and economic optimization of a solar-powered Stirling engine for micro-cogeneration purposes', Energy, Vol.111, pp. 1-17,2016.

Flynn, G., Percival, W. H. and Heffner, F. E. 'GMR Stirling thermal engine part of the Stirling engine story-1960 chapter', SAE Technical Papers, pp. 665-684.1960.

Guglielmo Ventura, L. R., The Art of Cryogenics, Journal of Chemical Information and Modeling. Elsevier. 2008.

Gussoli, M. K., Oliveira, J. C. D. de and Higa, M. 'Investigation on Volume Variation for 
Alpha Stirling Engines on Isothermal Model', Revista de Engenharia Térmica, Vol.19, No.2,2020.

Maogang He, Xinxin Zhang, Ke Zeng , Ke Gao 'A combined thermodynamic cycle used for waste heat recovery of internal combustion engine', Energy. Vol.36,No.12, pp. 6821$6829,2011$.

Klaus D. Timmerhaus, R. P. R., Cryogenic Engineering, Shinku/Journal of the Vacuum Society of Japan. Edited by K. D. Timmerhaus and R. P. Reed. New York, NY: Springer New York (International Cryogenics Monograph Series).2007.

McDonald, C. F. and Wilson, D. G., 'The utilization of recuperated and regenerated engine cycles for high-efficiency gas turbines in the 21st century', Applied Thermal Engineering, Vol.16, No.(8-9), pp. 635-653, 1996.

Nellis, G. F. and Maddocks, J. R., 'An isothermal model of a hybrid Stirling/reverse-Brayton cryocooler’, Cryogenics, Vol.43, No.1, pp. 31-43,2003.

Organ, A. J., 'Isothermal Stirling Cycle With Arbitrary Equation of State.', J Mech Eng Sci, Vol.21,No.1, pp. 51-56,1979.

Van Sciver, S. W. ,Helium Cryogenics, New York, NY: Springer New York, 2012

Senft, J. R., 'Mechanical efficiency of kinematic heat engines', Journal of the Franklin Institute, Vol.324,No.2, pp. 273-290, 1987.

Shaowei, Z., Peiyi, W. and Zhongqi, C. 'Double inlet pulse tube refrigerators: an important improvement', Cryogenics, Vol.30,No.6, pp. 514-520. 1990.

Sterling engine - Iran Khodro engine research, design and production company information portal. Available at: https://www.ip-co.com/projects/موتور -استرلينح/ (Accessed: 26 August 2021).

Stirling School of Engines, Available at: http://stirlingmotor.ir/ (Accessed: 25 August 2021).

Thombare, D. G. and Verma, S. K. 'Technological development in the Stirling cycle engines', Renewable and Sustainable Energy Reviews, Vol.12,No.1, pp. 1-38. 2008.

Tlili, I. 'A numerical investigation of an alpha stirling engine using the ross yoke linkage', International Journal of Heat and Technology, Vol.30,No.1, pp. 23-35. 2012.

Vineeth C S (2011) Stirling engines: A beginners guide, Energy Conversion, Second Edition. Edited by D. Y. Goswami and F. Kreith. Second edition. | Boca Raton : CRC Press, 2017.Series: Vineeth CS.

Walker, G. 'An Optimization of the Principal Design Parameters of Stirling Cycle Machines', Journal of Mechanical Engineering Science, Vol.4,No. 3, pp. 226-240, 1962.

Walker, G. 'Stirling cycle cooling engine with two-phase, two-component working fluid', Cryogenics, Vol.14,No.8, pp. 459-462.1974.

Walker, G. ‘Stirling engines. Oxford'. Clarendon Press. 1980.

Zhu, S. W. and Chen, Z. Q. 'Isothermal model of pulse tube refrigerator', Cryogenics, Vol.34,No.7, pp. 591-595. 1994. 